implant thực tế được cấy ghép có sử dụng MHDPT. Có thể nhấn mạnh rằng trong quá trình thu nhận, xử lý và thao tác hình ảnh, các sai số hoàn toàn có thể xảy ra. Các lỗi cũng có thể xảy ra trong quá trình sản xuất MHDPT trong giai đoạn mô phỏng phấu thuật trên phần mềm, về độ chính xác của máy tạo mẫu, trong các đặc tính của vật liệu được sử dụng, ở sự phù hợp giữa các trụ của hướng dẫn, mũi khoan của hệ thống cấy ghép. Các lối sản xuất có thể có tác động tích lũy, có thể tạo ra các kết quả lâm sàng không thuận lợi. Việc lựa chọn mô nâng đõ̃ MHDPT cũng góp phần làm thay đổi vị trí implant thực tế so với implant trong kế hoạch ban đầu.

\section{KẾT LUÂ̂N}

Implant được sử dụng cây ghép ở vùng mất răng phía trước hàm trên và vùng mất răng phía trước hàm dưới có chiều dài từ $10 \mathrm{~mm}$ đến $14 \mathrm{~mm}$, chủ yếu là $12 \mathrm{~mm}$; có đường kính chủ yếu là $3,6 \mathrm{~mm}$ và $4,0 \mathrm{~mm}$.

Lực vặn implant tối đa khi cấy ghép implant sớm lành thương mô mềm tại vùng mất răng phía trước hàm trên và hàm dưới trung bình là $58,03 \pm 9,095 \mathrm{~N} / \mathrm{cm}$, cho phép implant có độ ổn định ban đầu tốt, góp vai trò quan trọng trong việc tích hợp xương thành công.

Khi thực hiện cấy ghép implant sớm lành thương mô mềm vùng răng trước có sử dụng máng hướng dẫn phẫu thuật, vị trí implant thực tế so với implant kế hoạch có độ lệch góc là 7,79 $\pm 4,79$, độ lệch vị trí platform là $1,82 \pm 1,29$, độ lệch vị trí chóp implant là $2,42 \pm 1,35$. Sự khác biệt độ lệch không có sự khác biệt giữa các vị tría mất răng hàm trên và hàm dưới, không có sự khác biệt giữa các mật độ xương khác nhau.

\section{TÀI LIÊU THAM KHẢO}

1. Fang $Y$, An $X$, Jeong S.M, Choi B.H. Accuracy of computer-guided implant placement in anterior regions. J Prosthet Dent 2019;121(5):836-842 (https://doi.org/10.1016/j.prosdent.2018.07.015).

2. Schelbert $T$, Gander $T$, Blumer $M$, et al. Accuracy of 'Computer-Guided Template-Based Implant Surgery: A Computed Tomography-Based Clinical Follow-Up Study. Implant Dent 2019;28(6):556-563 (https://doi.org/10.1097/ID.0000000000000936).

3. Đàm Văn Việt (2013), Nghiên cứu điều trị mất răng hàm trên tưng phần bằng kỹ thuật implant có ghép xương.

4. Magrin GL, Rafael SNF, Passoni BB, Magini RS, Benfatti CAM, Gruber $\mathbf{R}$, et al. Clinical and tomographic comparison of dental implants placed by guided virtual surgery versus conventional technique: A split-mouth randomized clinical trial. J Clin Periodontol. 2020;47:120-8 (https://doi.org/10.1111/jcpe.13211).

5. Stübinger $S$, Buitrago-Tellez $C$, Cantelmi G. Deviations between placed and planned implant positions: An accuracy pilot study of skeletally 23 . supported stereolithographic surgical templates. Clin Implant Dent Relat Res 2014;16:540-51 (https://doi.org/10.1111/cid.12019).

6. Ta Đông Quận. So sánh hai hề thống máng hướng dấn phẩu thuật: in 3D và thủ công trong cấy ghép nha khoa răng trước hàm trên. Published online 2020.

7. Raes F, Cosyn J, De Bruyn H. Clinical, aesthetic, and patient-related outcome of immediately loaded single implants in the anterior maxilla: a prospective study in extraction sockets, healed ridges, and grafted sites. Clin Implant Dent Relat Res. 2013;15 (6):819-835.

8. Bùi Việt Hùng. Nghiên cứu phẫu thuật và đánh giá kết quả cây ghẹp nhóm răng trước. Published online 2017.

9. Neugebauer J, Traini T, Thams U, Piattelli A, Zöller J E. Peri-implant bone organization under immediate loading state. Circularly polarized light analyses: a minipig study. J Periodontol. 2006;77(2):152-160.

\title{
ĐĂC ĐIỂM LÂM SÀNG HÀNH VI TỰ SÁT Ở BỆNH NHÂN RỐI LOẠN CẢM XÚC LƯỡNG CỰC
}

\section{TÓM TẮT}

Đắt vấn đề: Rối loạn cảm xúc lưỡng cực là bệnh nội sinh, mạn tính, ngay cả khi điều trị thì khoảng

\footnotetext{
${ }^{1}$ Trường Đại học Y Hà Nội

²Bệnh viện Tâm Thần Hà Nội

Chịu trách nhiệm chính: Trần Quyết Thắng

Email: tranthang72@gmail.com

Ngày nhận bài: 11.8.2021

Ngày phản biện khoa học: 6.10.2021

Ngày duyệt bài: 14.10.2021
}

\section{Trần Quyết Thắng ${ }^{2}$, Nguyễn Văn Tuấn ${ }^{1}$}

$37 \%$ bệnh nhân tái phát thành trâm cảm hoặc hưng cảm trong vòng 1 năm và $60 \%$ tái phát trong vòng 2 năm, là một trong số mười nguyên nhân hàng đâu gây ra khuyết tật trên toàn thế giới năm 1990. Trên thế giới đã có nhiều nghiên cứu về tự sát và tự sát ở bệnh nhân trầm cảm nhưng chưa có nhiều nghiển cứu về tự sát trên rối loạn cảm xúc lưỡng cực. Vì vâyy để phục vụ thực hành lâm sàng và phát hiện sớm để kịp thời điêuu trị, từ đó giúp giảm gánh nặng chăm sóc, chúng tôi tiến hành nghiên cứu "Đặc điểm lâm sàng hành vi tự sát ở bệnh nhân rối loạn cảm xúc lưỡng cực" với mục tiêu: Mố tả đặc điểm lẩm sàng tự sát ở bệnh nhân rối loạn cảm xúc lưỡng cực. Đối tượng và phương 
pháp nghiên cứu: Nghiên cứu cắt ngang 39 bệnh nhân rối loạn cảm xúc lưỡng cực có tự sát trong 102 bệnh nhân được chẩn đoán rối loạn lưỡng cực được điều trị tại bệnh viện Tâm thần Hà Nội, bệnh viện Tâm thần Mỹ Đức, Viện sức khỏe Tâm thân Quốc gia từ tháng $12 / 2020$ đến tháng $8 / 2021$. Kết quả: có $38,223 \%$ bệnh nhân có tự sát, trong đó tỷ lệ bệnh nhân nam chiếm $64,1 \%$, bệnh nhân nữ chiếm 35,9\%. Trong nhóm tư sát bệnh nhân thất nghiêp chiếm $69,23 \%$, tỷ lệ tiền sử bệnh lý tâm thần của gia đình là $15,38 \%$, độ tuổi trung bình 41,97 $\pm 13,31$, thời gian mắc bệnh trung bình $12,31 \pm 9,14$, tuổi khởi phát trung bình $29,67 \pm 11,23$, giai đoạn hưng cảm chiếm $84,62 \%, 100 \%$ không điêu trị hoặc điều trị không đều, có ý tưởng tư sát bênh nhân giai đoan hưng cảm chiếm $84,62 \%$, trẩm cảm chiếm $15,38 \%, 48,72 \%$ xuất hiên ý tưởng tự sát cả ngày và đêm, $7,69 \%$ xuất hiện vào ban đêm, Thang điểm Miller trung bình của nhóm bệnh nhân ý tưởng tự sát là 18,26 \pm 9,514.

Từ khóa: Rối loạn lưỡng cực, tự sát

\section{SUMMARY}

\section{CLINICAL CHARACTERISTICS OF SUICIDE BEHAVIOR IN PATIENTS WITH BIPOLAR DISORDER}

Background: Bipolar affective disorder is an endogenous, chronic disease. Even with treatment, about $37 \%$ of patients relapse into depression or mania within 1 year and $60 \%$ relapse within 2 years, was one of the top ten leading causes of disability worldwide in 1990 . There have been many studies on suicide and suicide in patients with depression worldwide, but not many studies on suicide in the world. bipolar affective disorder. Therefore, in order to serve clinical practice and early detection for timely treatment, thereby helping to reduce the burden of care, we conducted the study "Clinical characteristics of suicidal behavior in patients with affective disorder". bipolar" with the objective: To describe the clinical characteristics of suicide in patients with bipolar affective disorder. Subjects and methods: Crosssectional study of 39 patients with bipolar affective disorder who committed suicide in 102 patients diagnosed with bipolar disorder treated at Hanoi Psychiatric Hospital, Psychiatric Hospital. My Duc, National Institute of Mental Health from December 2020 to August 2021. Results: $38.223 \%$ of patients committed suicide, of which male patients accounted for $64.1 \%$, female patients accounted for $35.9 \%$. In the suicide group, unemployed patients accounted for $69.23 \%$, the rate of family history of mental illness was $15.38 \%$, the mean age was $41.97 \pm 13.31$, the mean duration of illness was 12. ,31 \pm 9.14, mean age of onset $29.67 \pm 11.23$, manic episode accounted for $84.62 \%, 100 \%$ untreated or irregularly treated, patients with suicidal ideation stage mania accounted for $84.62 \%$, depression accounted for $15.38 \%$, $48.72 \%$ had suicidal ideation day and night, $7.69 \%$ appeared at night, average Miller scale of patient group suicidal ideation was $18.26 \pm 9.514$.

Keywords: Bipolar disorder, suicide

\section{I. ĐẶT VẤN ĐỀ}

Rối loạn cảm xúc lưỡng cực gặp tỷ lệ 1,5-2\% dân số, thường khởi phát ở tuổi trẻ (20-30 tuổi) bằng các giai đoạn trầm cảm $(60 \%)$, đưa vào cùng với bốn tình trạng tâm thần khác, là một trong số mười nguyền nhân hàng đâu gây ra khuyết tật trên toàn thế giới năm 1990, được đo bằng những năm bị khuyết tật.

Khoảng $75 \%$ các bệnh nhân hưng cảm có hành vi tấn công hoặc đe dọa ở một số thời gian. Bệnh nhân hưng cảm có nguy cơ tự tử cao hơn. Tuy nhiên, hầu hết nguy cơ đáng kể dường như là khi bệnh nhân lưỡng cực bị trầm cảm.

Trong lĩnh vực tâm thần học, tự sát là vấn đề thường gặp, đứng hàng đầu trong các nguyên nhân gây ra tử vong, và liên quan đến nhiêu bệnh lý tâm thần khác nhau. Theo Sadock $B . J$ (2015), 95\% các trường hợp tự sát có ít nhất một rối loạn tâm thần tại thời điểm tự sát. Các rối loạn tâm thần hay gặp nhất là trầm cảm, tâm thần phân liệt, rối loạn lo âu, rối loạn lưỡng cực, nghiện rượu và ma túy, kể cả động kinh và nhân cách bệnh. ${ }^{4}$

Vì vậy để phục vụ thực hành lâm sàng và phát hiện sớm để kịp thời điều trị, từ đó giúp giảm gánh nặng chăm sóc, chúng tôi tiến hành nghiên cứu "Đặc điểm lâm sàng hành vi tự sát ở bệnh nhân rối loạn cảm xúc lưỡng cực" với mục tiểu: Mô tả đặc điểm lâm sàng tự sát ở bệnh nhân rối loạn cảm xúc lưỡng cực.

\section{II. ĐỐI TƯỢNG VÀ PHƯƠNG PHÁP NGHIÊN CỨU}

2.1. Đối tượng nghiên cứu. Bệnh nhân được chẩn đoán rối loạn cảm xúc lưỡng cực có ý tưởng hoặc hành vi tự sát điều trị nội trú tại Viện Sức khỏe Tâm thần Bach Mai và Bệnh viện Tâm thần Hà Nội, Bệnh viện Tâm thần Mỹ Đức thời gian từ tháng 12 năm 2020 đến tháng 8 năm 2021.

\subsubsection{Tiêu chuẩn lựa chọn bệnh nhân} nghiên cứu

- Bệnh nhân được chẩn đoán rối loạn cảm xúc lưỡng cực, có ý tưởng hoăcc hành vi tự sát.

- Bệnh nhân và người nhà tự nguyện đồng ý tham gia nghiên cứu.

\subsubsection{Tiêu chuẩn loại trừ}

Không chọn bệnh nhân vào nhóm nghiên cứu khi:

- Bệnh nhân không hợp tác trả lời hết được bộ câu hỏi.

- Bệnh nhân có sử dụng rượu, ma túy.

- Bệnh nhân mắc bệnh nội khoa nặng.

\subsection{Phương pháp nghiên cứu.}

\subsubsection{Thiết kế nghiến cứu}

- Sử dụng phương pháp nghiên cứu cắt ngang. Những bệnh nhân đáp ứng tiêu chuẩn lựa chọn và tiêu chuẩn loại trừ ở trên được đưa 
vào nghiên cứu.

- Các đối tượng được nghiên cứu theo một mẫu bệnh án thống nhất.

\subsubsection{Cỡ mẫu nghiên cứu}

Cõ̃ mẫu được tính theo công thức "Ước tính một tỉ lệ trong quần thể":

$$
n=Z_{(1-\alpha / 2)}^{2} \frac{p(1-p)}{\Delta^{2}}
$$

Nghiên cứu này thực hiện trên tổng số 102 bệnh nhân chẩn đoán rối loạn cảm xúc lưỡng cực trong đó có 39 bệnh nhân có ý tưởng, hành vi tư sát.

\subsubsection{Công cụ chẩn đoán và đánh giá}

\section{KẾT QUẢ NGHIÊN CỨU}

Bảng 3.1. Đặc điểm giới, trinh độ học vấn, nghề nghiệp.

\begin{tabular}{|c|c|c|c|c|c|c|c|}
\hline \multirow{2}{*}{\multicolumn{2}{|c|}{ Đặc điểm }} & \multicolumn{2}{|c|}{ Tự sát (n = 39) } & \multicolumn{2}{|c|}{ Không tự sát ( $n=63)$} & \multicolumn{2}{|c|}{ Tống số ( $\mathrm{n=102)}$} \\
\hline & & $\mathbf{n}$ & $\%$ & $\mathrm{n}$ & $\%$ & $n$ & $\%$ \\
\hline \multirow{2}{*}{ Giới } & Nữ & 14 & 35,90 & 30 & 47,62 & 44 & 43,14 \\
\hline & Nam & 25 & 64,10 & 33 & 52,38 & 58 & 56,86 \\
\hline \multirow{4}{*}{$\begin{array}{l}\text { Trình độ } \\
\text { học vấn }\end{array}$} & TH trở xuống & 2 & 5,13 & 13 & 20,63 & 15 & 14,71 \\
\hline & THCS & 18 & 46,15 & 28 & 44,44 & 46 & 45,10 \\
\hline & THPT & 18 & 46,15 & 17 & 26,98 & 35 & 34,31 \\
\hline & $\mathrm{CĐ}, \mathrm{ÐH}$ & 1 & 2,56 & 5 & 7,94 & 6 & 5,88 \\
\hline \multirow{4}{*}{$\begin{array}{l}\text { Nghề } \\
\text { nghiệp }\end{array}$} & Thất nghiệp & 27 & 69,23 & 27 & 42,86 & 54 & 52,94 \\
\hline & $\mathrm{CN}, \mathrm{VC}$ & 2 & 5,13 & 9 & 14,29 & 11 & 10,78 \\
\hline & Nông dân & 3 & 7,69 & 5 & 7,94 & 8 & 7,84 \\
\hline & Nghề khác & 7 & 17,95 & 22 & 34,92 & 29 & 28,43 \\
\hline \multirow{3}{*}{$\begin{array}{l}\text { Hôn } \\
\text { nhân }\end{array}$} & Độc thân & 16 & 41,03 & 21 & 33,33 & 37 & 36,27 \\
\hline & Kết hôn & 21 & 53,85 & 35 & 55,56 & 56 & 54,90 \\
\hline & Ly thân, ly hôn & 2 & 5,13 & 7 & 11,11 & 9 & 8,82 \\
\hline \multirow{4}{*}{$\begin{array}{l}\text { Tiền sử } \\
\text { gia đình } \\
\text { bệnh Tा }\end{array}$} & Không & 33 & 84,62 & 47 & 74,60 & 80 & 78,43 \\
\hline & Bố, mẹ & 2 & 5,13 & 6 & 9,52 & 8 & 7,84 \\
\hline & Anh, chị, em & 3 & 7,69 & 5 & 7,94 & 8 & 7,84 \\
\hline & Khác & 1 & 2,56 & 5 & 7,94 & 6 & 5,88 \\
\hline \multicolumn{4}{|c|}{$\begin{array}{l}\text { Nhân xét: - Giới tính: Trong nhóm bệnh } \\
\text { nhân có tự sát tỷ lệ bệnh nhân nam chiếm } \\
\text { 64,1\%, bệnh nhân nữ chiểm } 35,9 \% \text {. } \\
\text { - Trình độ học vấn: nhóm có trình độ THCS } \\
\text { và THPT chiếm đa số, nhóm có tự sát chiếm } \\
92,3 \% \text {, nhóm không có tứ sát chiếm } 79,41 \% \text {. } \\
\text { - Nghề nghiệp: đa số bệnh nhân đều trong } \\
\text { tình trạng thất nghiệp, nhóm có tự sát bệnh }\end{array}$} & \multicolumn{4}{|c|}{$\begin{array}{l}\text { nhân thất nghiêpp chiếm } 69,23 \% \text {, nhóm không có } \\
\text { tự sát chiếm } 52,94 \% \text {. } \\
\text { - Số bệnh nhân đã kết hôn ở cả } 2 \text { nhóm có tự } \\
\text { sát và không tự sát chiếm tỳ lệ cao nhất là } \\
53,85 \% \text { và } 55,56 \% \text {. } \\
\text { - Trong nhóm bệnh nhân tự sát số bệnh nhân } \\
\text { không có tiền sử bểnh lý gia đình chiếm } 84,62 \% \text {, } \\
\text { nhóm không tự sát là } 74,6 \% \text {. }\end{array}$} \\
\hline \multicolumn{8}{|c|}{ Bảng 3.2. Đặc điểm về tuổi nhóm bệnh nhân. } \\
\hline \multirow[b]{2}{*}{ Số TT } & & nh nhân & \multicolumn{2}{|c|}{ Có tư sát } & \multicolumn{2}{|c|}{ Không tự sát } & \multirow[b]{2}{*}{$\mathbf{p}$} \\
\hline & & & $\mathbf{n}$ & Tỷ lệ \% & $\mathbf{n}$ & Tỷ lệ \% & \\
\hline 1 & \multicolumn{2}{|l|}{$\leq 30$ tuối } & 8 & 20,51 & 13 & 20,63 & \multirow{4}{*}{0,006} \\
\hline 2 & \multicolumn{2}{|l|}{$31-40$ tuối } & 12 & 30,77 & 16 & 25,40 & \\
\hline 3 & \multicolumn{2}{|l|}{$41-50$ tuối } & 9 & 23,08 & 15 & 23,81 & \\
\hline 4 & \multicolumn{2}{|l|}{$>50$ tuối } & 10 & 25,64 & 19 & 30,16 & \\
\hline \multirow{2}{*}{\multicolumn{3}{|c|}{$\begin{array}{l}\text { Tống số } \\
\text { fi trung b }\end{array}$}} & 39 & 100,0 & 63 & 100,00 & \\
\hline & & & 41,97 & 13,31 & $43,6 \pm$ & 15,1 & \\
\hline
\end{tabular}

Nhận xét. - Nhóm bệnh nhân có tự sát ở độ tuối 31-40 chiếm tỷ lệ cao nhất là 30,77\%, độ tuổi dưới 30 chiếm tỷ lệ thấp nhất 20,51\%.
- Bảng phân loại bệnh Quốc tế (ICD10 năm 1992)

- Sử dụng bệnh án của bệnh nhân đã được hội chẩn và điều trị tại viện.

- Sử dụng bệnh án thiết kế cho nghiên cứu.

- Thang điểm Beck, YMRS, Miller.

2.3 Đạo đức nghiên cứu: Người bệnh được giải thích mục đích của nghiên cứu trước khi tham gia, các thông tin do người bệnh cung cấp được đảm bảo giữ bí mật.Người bệnh không phải chi trả bất cứ chi phí khám bệnh, trắc nghiệm tâm lý. Nghiên cứu đã được thông qua của hội đồng đạo đức trường Đại học Y Hà Nội và cơ sở nghiên cứu. 
- Nhóm bệnh nhân không tự sát ở độ tuổi trên 50 chiếm tỷ lệ cao nhất là 30,16\%, thấp nhất là nhóm dưới 30 tuổi chiếm tỷ lệ $20,63 \%$

Bảng 3.3. Đặc điểm về tuối khởi phát

\begin{tabular}{|c|c|c|c|c|c|c|}
\hline \multirow[b]{2}{*}{ Số TT } & \multirow{2}{*}{ Tuổi khởi phát Bệnh nhân } & \multicolumn{2}{|c|}{ Có tự sát } & \multicolumn{2}{|c|}{ Không tự sát } & \multirow[b]{2}{*}{$\mathbf{p}$} \\
\hline & & $\mathbf{n}$ & Tỷ lệ \% & $\mathbf{n}$ & Tỷ lệ \% & \\
\hline 1 & $\leq 20$ tuối & 11 & 28,21 & 13 & 20,63 & \multirow{4}{*}{0,07} \\
\hline 2 & $21-30$ tuối & 9 & 23,08 & 24 & 38,10 & \\
\hline 3 & $31-40$ tuối & 10 & 25,64 & 14 & 22,22 & \\
\hline 5 & $>40$ tuối & 9 & 23,08 & 12 & 19,05 & \\
\hline \multirow{2}{*}{\multicolumn{2}{|c|}{$\begin{array}{c}\text { Tổng số } \\
\text { Tuối trung bình }\end{array}$}} & 39 & 100,0 & 63 & 100,0 & \\
\hline & & \multicolumn{2}{|c|}{$29,67 \pm 11,23$} & \multicolumn{2}{|c|}{$30,40 \pm 12,17$} & \\
\hline
\end{tabular}

Nhận xét. - Nhóm bệnh nhân tự sát có tuổi khởi phát bệnh dưới 20 chiếm tỷ lệ cao nhất 28,21\%.

- Nhóm bệnh nhân không tự sát có tuổi khởi phát 21-30 chiếm tỷ lệ cao nhất $38,10 \%$, thấp nhất là khởi phát trên 40 chiếm tỷ lệ 19,05\%.

- Sự khác biệt này không có ý nghĩa thông kê với $p=0,07$

Bảng 3.4. Đặc điểm về thể bệnh nhóm nghiên cứu.

\begin{tabular}{|c|c|c|c|c|c|c|}
\hline \multirow[b]{2}{*}{ Số TT } & \multirow{2}{*}{ Thể bệnh Bệnh nhân } & \multicolumn{2}{|c|}{ Có tự sát } & \multicolumn{2}{|c|}{ Không tự sát } & \multirow[b]{2}{*}{$\mathbf{p}$} \\
\hline & & $\mathbf{n}$ & Tỷ lệ \% & $\mathbf{n}$ & Tỷ lệ \% & \\
\hline 1 & Giai đoạn hưng cảm & 33 & 84,62 & 43 & 97,73 & \multirow{2}{*}{0,397} \\
\hline 2 & Giai đoan trâm cảm & 6 & 15,38 & 1 & 2,27 & \\
\hline & Tống số & 39 & 100,0 & 44 & 100,0 & \\
\hline
\end{tabular}

Nhận xét. - Ơ̛ cả 2 nhóm bệnh nhân có tự sát và không tự sát, bệnh nhân chấn đoán giai đoạn hưng cảm đều chiếm đa số với tỷ lệ $84,62 \%$ và $97,73 \%$.

- Sự khác biệt không có ý nghĩa thông kê với $p=0,397$

Bảng 3.5. Mối liên quan các thể bệh và múc độ tự sát

\begin{tabular}{|c|c|c|c|c|}
\hline \multirow{2}{*}{ Thể bệnh } & \multicolumn{2}{|c|}{ Yư tưởng TS } & \multicolumn{2}{c|}{ Kế hoạch và hành động TS } \\
\cline { 2 - 5 } & $\mathbf{n = 3 9}$ & Tỷ lệ \% & $\mathbf{n}=\mathbf{1 5}$ & Tỷ lệ \% \\
\hline GĐ hưng cảm & 33 & 84,62 & 13 & 86,67 \\
\hline GĐ trầm cảm & 6 & 15,38 & 2 & 13,33 \\
\hline Tống số & $\mathbf{3 9}$ & $\mathbf{1 0 0 , 0}$ & $\mathbf{1 5}$ & $\mathbf{1 0 0 , 0}$ \\
\hline
\end{tabular}

Nhận xét. - Trong tống số 39 bệnh nhân tự sát nghiên cứu, có 39 bệnh nhân có ý tưởng tự sát, 15 bệnh nhân đã lên kế hoạch tự sát và 3 bệnh nhân thực hiện hành vi tự sát.

- Nhóm có ý tưởng tự sát bệnh nhân giai đoạn hưng cảm chiếm $84,62 \%$, trầm cảm chiếm $15,38 \%$.

Bảng 3.6. Môi liên quan giới tính và mức độ tự sát

\begin{tabular}{|c|c|c|c|c|}
\hline \multirow{2}{*}{ Giới tính sát } & \multicolumn{2}{|c|}{ Ý tưởng TS } & \multicolumn{2}{c|}{ Kế hoạch và hành động TS } \\
\cline { 2 - 5 } & $\mathbf{n = 3 9}$ & $\mathbf{\%}$ & $\mathbf{n = 1 5}$ & $\mathbf{1 0}$ \\
\hline Nam & 14 & 35,90 & 6 & 40,00 \\
\hline Nữ & 25 & 64,10 & 9 & 60,00 \\
\hline Tống số & $\mathbf{3 9}$ & $\mathbf{1 0 0}$ & $\mathbf{1 5}$ & $\mathbf{1 0 0}$ \\
\hline
\end{tabular}

Nhận xét. - Trong tống số 39 bệnh nhân nghiên cứ có ý tưởng tự sát, nữ giới là 25 bệnh nhân, chiếm tỷ lệ 64,10\%, nam giới chiếm 35,90\%.

- Trong số 15 bệnh nhân có kế hoạch tự sát nữ giới chiếm 60\%.

- Trong số 3 bệnh nhân thực hiện hành vi tự sát nữ giới chiếm 66,67\%.

- Trong số 14 bệnh nhân nam nghiên cứu, $100 \%$ bệnh nhân có ý tưởng tự sát, $42,86 \%$ có kế hoạch tự sát và $7,14 \%$ thực hiện hành vi tự sát.

- Trong số 25 bệnh nhân nữ nghiên cứu, 100\% bệnh nhân có ý tưởng tự sát, 36\% có kế hoạch tự sát và $5,56 \%$ thực hiện hành vi tự sát.

Bảng 3.7. Mối liền quan các triệu chứng loạn thần và mức độ tự sát.

\begin{tabular}{|c|c|c|c|c|c|}
\hline \multirow{2}{*}{ Loạn thần } & Tự sát & \multicolumn{2}{|c|}{ Y tưởng TS } & \multicolumn{2}{c|}{ Kế hoạch và hành động TS } \\
\cline { 3 - 6 } & & $\mathbf{n = 3 9}$ & $\mathbf{\%}$ & $\mathbf{n}=\mathbf{1 5}$ & $\mathbf{\%}$ \\
\hline \multirow{2}{*}{$\begin{array}{c}\text { Hoang } \\
\text { tưởng }\end{array}$} & Có & 31 & 79,49 & 13 & 86,67 \\
\cline { 2 - 6 } & Không & 8 & 20,51 & 2 & 13,33 \\
\hline Áo giác & Có & 3 & 7,69 & 2 & 13,33 \\
\hline
\end{tabular}




\begin{tabular}{|c|c|c|c|c|c|}
\hline & Không & 36 & 92,31 & 13 & 86,67 \\
\hline \multirow{2}{*}{$\begin{array}{c}\text { Chi phối } \\
\text { hành vi }\end{array}$} & Có & 30 & 96,77 & 13 & 100,00 \\
\cline { 2 - 5 } & Không & 1 & 3,23 & 0 & 0 \\
\hline
\end{tabular}

Nhận xét: - Trong nhóm bệnh nhân có ý tưởng tự sát bệnh nhân có hoang tưởng, chiếm $79,49 \%$, bệnh nhân có ảo giác chiếm $7,96 \%$ và $96,77 \%$ triệu chứng loạn thần này chi phối hành vi của bệnh nhân.

- Trong nhóm bệnh nhân có kế hoạch tự sát bệnh nhân có hoang tưởng chiếm 86,67\%, có 2 bệnh nhân có ảo giác chiếm $13,33 \%$ và $100 \%$ các triệu chứng loạn thần này chi phối hành vi của bệnh nhân.

Bảng 3.8. Môi liên quan thời gian bị bệnh và tự sát

\begin{tabular}{|c|c|c|c|c|}
\hline \multirow{2}{*}{ Thời gian mắc bệnh Bệnh nhân } & \multicolumn{2}{|c|}{ Y tưởng tự sát } & \multicolumn{2}{|c|}{ Kế hoạch và hành động TS } \\
\hline & $n=39$ & Tỷ lệ \% & $n=15$ & Tỷ lệ \% \\
\hline$\leq 5$ & 9 & 23,08 & 2 & 13,33 \\
\hline $6-10$ & 9 & 23,08 & 6 & 40,00 \\
\hline $11-15$ & 11 & 28,21 & 3 & 20,00 \\
\hline$>15$ & 10 & 25,64 & 4 & 26,67 \\
\hline Tổng số & 39 & 100,0 & 15 & 100,0 \\
\hline
\end{tabular}

Nhận xét: - Nhóm bệnh nhân ý tưởng tự sát có thời gian mắc bệnh dưới 5 năm và $6-10$ năm có số lượng ít nhất là 9 bệnh nhân, chiếm tỷ lệ 23,08\%.

- Nhóm bệnh nhân kế hoạch tự sát thời gian mắc bệnh 2 năm có số lượng bệnh nhân thấp nhất là 2 bệnh nhân chiếm tỷ lệ 13,33\%, cao nhất là có thời gian mắc bệnh từ 6-10 năm là 6 bệnh nhân, chiếm tỷ lệ $40 \%$.

Bảng 3.9. Mối liên quan thang điểm Miller và tự sát

\begin{tabular}{|c|c|c|c|c|}
\hline \multirow{2}{*}{ Miller Tư sát } & \multicolumn{2}{|c|}{$\bar{Y}$ tưởng } & \multicolumn{2}{|c|}{ Kế hoạch } \\
\hline & $\mathbf{n}$ & $\%$ & $\mathbf{n}$ & $\%$ \\
\hline$<19$ & 24 & 61,54 & 2 & 13,33 \\
\hline $19-36$ & 14 & 35,90 & 12 & 80,00 \\
\hline$>36$ & 1 & 2,56 & 1 & 6,67 \\
\hline Trung bình & & & & \\
\hline
\end{tabular}

Nhận xét: - Nhóm bệnh nhân ý tưởng tự sát có 24 bệnh nhân chiếm $61,54 \%$ có thang điểm Miller mức độ tự sát nhẹ, có 1 bệnh nhân chiếm tỷ lệ 2,56\% có điểm Miller mức độ tự sát nặng. Thang điểm Miller trung bình của nhóm bệnh nhân ý tưởng tự sát là 18,26 \pm 9,514.

- Nhóm bênh nhân có kế hoạch tự sát có 12 bệnh nhân điểm Miller mức độ vừa chiếm tỷ lệ cao nhất là $80 \%$. Thang điểm Miller trung bình của nhóm bệnh nhân kế hoạch tự sát là 28,07 \pm 7,235.

- Qua bảng này thấy thang điểm Miller trung bình càng cao thì mức độ tự sát của bệnh nhân càng nặng.

\section{KẾT LUÂ̂N}

- Qua nghiên cứu 102 bênh nhân rối loạn lưỡng cực có 39 bệnh nhân có hành vi tự sát: 39 bệnh nhân có ý tưởng tự sát, trong đó có 15 bểnh nhân đã lên kế hoạch tự sát và đã có 3 bệnh nhân thực hiện hành vi tự sát.

- Nghề nghiệp: đa số bệnh nhân đều trong tình trạng thất nghiệp, nhóm có tự sát bệnh nhân thất nghiệp chiếm $69,23 \%$, nhóm không có tự sát chiếm $52,94 \%$.

- Số bệnh nhân đã kết hôn ở cả 2 nhóm có tự sát và không tự sát chiếm tỷ lệ cao nhất là $53,85 \%$ và $55,56 \%$.

- Trong nhóm bệnh nhân tự sát số bệnh nhân không có tiền sử bệnh lý gia đình chiếm 84,62\%, nhóm không tự sát là $74,6 \%$.

- Tuổi khởi phát trung bình của nhóm bệnh nhân có tự sát là $29,67 \pm 11,23$ tuổi và nhóm không tự sát là $30,40 \pm 12,17$ tuổi.

- Cả 2 nhóm bệnh nhân có tự sát và không tự sát, bệnh nhân chẩn đoán giai đoạn hưng cảm đều chiếm đa số với tỷ lệ $84,62 \%$ và $97,73 \%$.

- Ở cả 2 nhóm bệnh nhân có tự sát và không tự sát, bệnh nhân chẩn đoán giai đoạn hưng cảm đều chiếm đa số với tỷ lệ $84,62 \%$ và $97,73 \%$.

- Thang điểm Miller trung bình càng cao thì mức độ tự sát của bệnh nhân càng nặng.

\section{TÀI LIẸU THAM KHẢO}

1. Nguyễn Kim Việt. Rối loan cảm xúc lưỡng cực. Giáo trình bệnh học tâm thần. Nhà xuất bản Y học; 2016:66-73.

2. Kaplan \& Sadock. Bipolar Disorders. In: twelfth edition, ed. Kaplan \& Sadock's synopsis of psychiatry Wolters Kluwer; 2020.

3. American Psychiatric Ássociation. Bipolar and related disorders. Desk reference to the diagnostic criteria from DSM-5. 2013:65-92. 
4. Bùi Quang Huy. Rối loạn cảm xúc lưỡng cực. Nhà xuất bản Y hoc; 2009.

5. Tổ chức $\mathbf{Y}$ tể thế giới. Rối loan khí sắc. Phân loai bệnh quốc tế lần thứ 10 (PLBQT-10F) về các rối loan tâm thân và hành vi. Hà Nôi; 1992:79-105.

6. Nguyê̂n Văn Tường. Một số khái niệm về hành vi tự sát và hướng nghiên cứu trong tưởng lai. Tự sát và biện pháp phòng chống. Nhà xuất bản Y học; 2009:9-18.

7. Hansson $C_{\text {, Joas }} E_{\text {, Hawton }} K_{\text {, }}$ et al. Risk factors for suicide in bipolar disorder: a cohort study of 12850 patients. Acta Psychiatrica Scandinavica. 2018:456-463.

\section{THỰC TRANG SỬ DUUNG INTERNET Ở NGƯỜI BÊNH NÔ̂I TRÚ TỪ 10 ĐẾN 24 TUỔI TẠI VIỆN SỨC KHỎE TÂMM THẦN}

\section{TÓM TẮT}

Đăt vấn đề: Internet ngày nay là một phần không thể thiếu trong cuộc sống của chúng ta. Tuy nhiên, việc sử dụng Internet không đúng cách gây ra nhiều tác hại về sức khỏe, cần được sự quan tâm chú ý. Ớ Việt Niam, các nghiên cứu về vấn đề này còn hạn chế. Do đó, chúng tôi thực hiện nghiên cứu:" Thực trạng sử dụng Internet của người bệnh nội trú từ 10 đến 24 tuổi tại Viện Sức khỏe Tâm thân". Mục tiêu: "Mô tả thực trạng sử dụng Internet của người bệnh nội trú từ 10 đến 24 tuổi tại Viện Sức khỏe Tâm thân". Đối tượng và phương pháp nghiên cứu: Nghiên cứu mô tả cắt ngang có hôi cứu 109 người bệnh nội trú từ 10- 24 tuổi tại Viên Sức khỏe Tâm thần từ tháng 8/2020- 10/2021. Kết quả: Quần thể nghiên cứu có độ tuổi trung bình $18,72 \pm 3,76$, nữ giới chiếm tỉ lệ nhiều hơn $(57,8 \%)$, nơi sinh sống nhiêuu nhất là ở thành thị $(52,8 \%)$, nghề nghiệp chủ yếu là học sinh, sinh viên $(73,4 \%)$, trong đó nhiều nhất là bậc Trung học phổ thông $(45,9 \%)$. Tỉ lệ sử dụng Internet trong quần thể nghiên cứu là $100 \%$, trong đó có $37,6 \%$ người bênh được đánh giá là nghiện Internet theo thang điểm Chen Internet addiction scale (CIAS). Thời gian sử dụng Internet trung bình mối ngày thường và ngày nghỉ ở quần thể nghiên cứu tương ứng là $3,73 \pm$ 2,45 và $4,76 \pm 2,95$ giờ. Các hình thức được lựa chọn sử dụng nhiều nhất là mạng xã hội $(51,4 \%)$, chơi games online $(26,6 \%)$, xem phim- video ngắn giải trí $(14,7 \%)$. Kết luân: Thực trang sử dung Internet ở quần thể nghiên cứu là đa dạng về hình thức, mục đích, thời gian, với tỷ lệ sử dụng gây hại, nghiện cao. Vì vậy cần chú ý đến vấn đề quản lý sử dụng Internet ở nhóm đối tượng này.

Tư khóa: Internet, thực trạng sử dụng, nghiện Internet

\section{SUMMARY \\ THE REALITY OF INTERNET USE OF INPATIENTS AGED 10 TO 24 YEARS AT THE}

\author{
${ }^{1}$ Dại họ Y Hà Nọi \\ ${ }^{2}$ Viên Sức khoé Tâm thần - Bênh viện Bach Mai \\ Chịu trách nhiệm chính: Nguyễn Việt Hà \\ Email: havnguyenpsy94@gmail.com \\ Ngày nhận bài: 10.8.2021 \\ Ngày phản biên khoa hoc: 6.10 .2021 \\ Ngày duyệt bài: 14.10.2021
}

NATIONAL INSTITUTE OF MENTAL HEALTH

Background: The Internet today is an integral part of our lives. However, improper use of the Internet causes many health harms, which need attention. In Vietnam, researchs on this issue is still limited. Therefore, we conducted the study: "The reality of Internet use of inpatients aged 10 to 24 years at the National Institute of Mental Health". Objects: "Describe the reality of Internet use of inpatients aged 10 to 24 years at the National Institute of Mental Health". Subjects and methods: A retrospective cross-sectional descriptive study of 109 inpatients aged 10-24 years at the National Institute of Mental Health from August 2020 to October 2021. Results: The study population had an average age of $18.72 \pm 3.76$, women accounted for more (57.8\%), the largest living place was in urban areas (52.8\%), major occupations are students $(73.4 \%)$, of which the majority is at upper secondary level $(45.9 \%)$. The rate of Internet use in the study population is $100 \%$, of which $37.6 \%$ of patients are rated as Internet addiction according to the Chen Internet addiction scale (CIAS). The average time of using the Internet each weekday and rest day in the study group of patients was $3.73 \pm 2.45$ and $4.76 \pm 2.95$ hours, respectively. The forms chosen by the patient group the most are social networks $(51.4 \%)$, playing online games $(26.6 \%)$, watching movies and short videos for entertainment $(14.7 \%)$. Conclusion: The reality of Internet use in the study population is diverse in terms of form, purpose and time, with a high rate of harmful and addiction. Therefore, attention should be paid to the management of Internet use in this group.

Key words: Internet, Internet usage, Internet addiction

\section{I. ĐẠT VẤN ĐỀ}

Sự ra đời của Internet mang lại cho nhân loại những thành tựu vô cùng to lớn về mọi mặt: từ khoa học kĩ thuật, công việc chuyên môn, lợi ích kinh tể, cho đến giải trí, phục vụ đời sống thường ngày của con người... Chính vì những lợi ích lớn lao mà nó mang lại, sự hấp dẫn không thể chối từ đó đã khiến con người dành rất nhiều thời gian với Internet, kéo theo đó là những tác hại mà con người chưa thể lường trước được.

Theo báo cáo thống kê của Phòng Dân số Liên hợp quốc số lượng người sử dụng internet 